\title{
Documents codés, documents indéchiffrables
}

\section{Christophe Didier}

\section{(2) OpenEdition}

Journals

Édition électronique

URL : http://journals.openedition.org/rbnu/1458

DOl : $10.4000 /$ rbnu. 1458

ISSN : 2679-6104

\section{Éditeur}

Bibliothèque nationale et universitaire de Strasbourg

\section{Édition imprimée}

Date de publication : 1 mai 2016

Pagination : 6-7

ISBN : 9782859230623

ISSN : 2109-2761

\section{Référence électronique}

Christophe Didier, «Documents codés, documents indéchiffrables », La Revue de la BNU [En ligne], 13 | 2016, mis en ligne le 01 mars 2020, consulté le 12 décembre 2020. URL : http://

journals.openedition.org/rbnu/1458; DOI : https://doi.org/10.4000/rbnu.1458

\section{(C) $10(0$}

La Revue de la BNU est mise à disposition selon les termes de la Licence Creative Commons Attribution - Pas d'Utilisation Commerciale - Partage dans les Mêmes Conditions 4.0 International. 


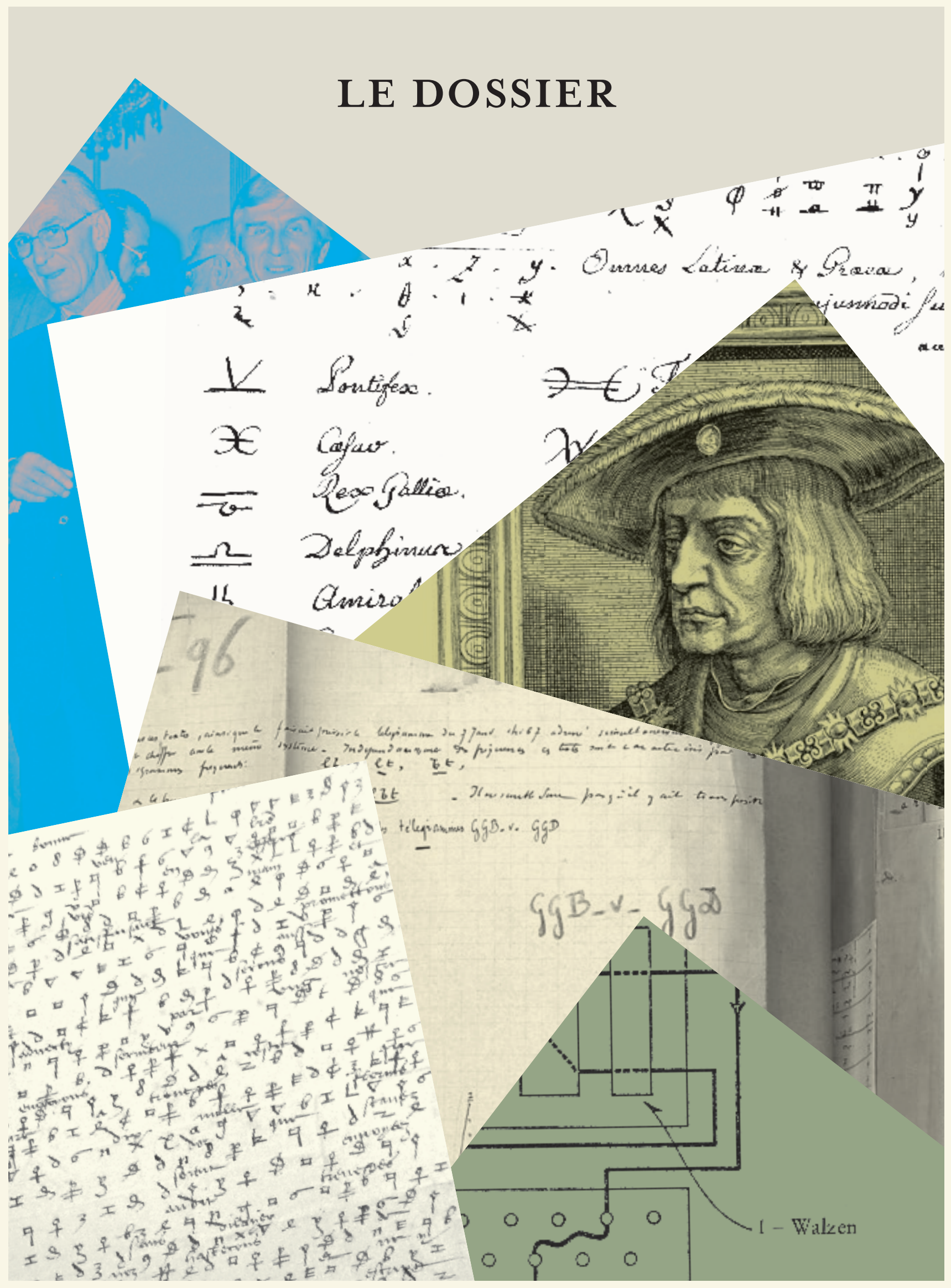




\section{Documents codés, documents indéchiffrables}

En 2015 s'est tenue au Musée Champollion de Figeac une exposition qui, sous le titre Cacher Coder. 4000 ans d'écritures secrètes, examinait les moyens mis en œuvre, presque concomitamment à l'invention de l'écriture et parcourant toutes les civilisations, pour dissimuler le sens des messages transmis, que ce soit par l'utilisation de signes jusqu'alors inconnus ou par une modification de l'utilisation de signes usuels. Presqu'en même temps, on pouvait voir à la Württembergische Landesbibliothek de Stuttgart une exposition retraçant les cent ans de sa section d'histoire contemporaine (la Bibliothek für Zeitgeschichte), dont un des objets-phares était un exemplaire de la fameuse machine Enigma, avec laquelle l'État-major allemand crypta ses messages radio pendant la Seconde Guerre mondiale. Et la dématérialisation croissante des transactions humaines nous rappelle tous les jours la présence de codes cryptés qui permettent de sécuriser nos échanges - tout comme leur dévoilement pourrait a contrario mettre à nu bon nombre de nos activités.

Le chiffrement / déchiffrement d'un message est une thématique qui sied particulièrement bien au monde des bibliothèques, lesquelles détiennent - et préservent ces précieux témoins d'une activité dont on découvrira, dans les pages qui suivent, l'importance qu'elle a pu revêtir au cours de l'Histoire. De façon plus générale, la bibliothèque est en elle-même un instrument de déchiffrement, mettant à disposition de ses lecteurs, avec les ouvrages qu'elle acquiert, autant de portes à ouvrir pour comprendre le monde qui nous entoure, le legs des civilisations d'hier et préparer ainsi les savoirs de demain. Encore faut-il se donner les moyens du déchiffrement...

Les pages qui suivent rappelleront quels efforts ont dû être produits pour retrouver le sens d'écritures oubliées - et partant, l'étude de la civilisation dont elles étaient porteuses -, lesquels sont parfois similaires à ceux qu'ont

déployés, au fil des siècles, les " cryptanalystes " ou autres " casseurs de codes " vis-à-vis des messages cryptés. Elles nous rappelleront aussi qu'un déchiffrement n'est jamais acquis, et que si la bibliothèque peut apparaître comme une forme de "tour de Babel des savoirs ", la connaissance des langues, anciennes et contemporaines, et la transmission desdits savoirs sont la condition nécessaire à son accessibilité. À l'heure où une ouverture accrue des bâtiments, une mise en libre accès plus grande des collections et la disponibilité numérique d'un nombre toujours croissant de sources primaires peuvent donner l'illusion d'un savoir définitivement disponible, il n'est pas inutile de rappeler que les outils d'accès à ce savoir se cultivent et s'entretiennent, et ne s'usent que si l'on ne s'en sert pas.

Avec ces réflexions sur les documents codés et les documents indéchiffrables, La Revue de la BNU poursuit son travail d'investigation sur ces thématiques " parabibliothéconomiques " qui rythment la vie de nombreux chercheurs et occasionnellement passionnent le grand public. Car quoi de plus fascinant qu'un code et que la démarche obstinée du chercheur tendant de toutes ses forces intellectuelles à son déchiffrement ? Les articles qui suivent en donneront quelques exemples - pour ne pas parler de la frustration stimulante engendrée par l'échec, comme le cas d'école du célèbre " manuscrit de Voynich " nous le rappelle périodiquement. Quoi de plus stratégique aussi, lorsque le déchiffrement devient partie prenante d'enjeux géopolitiques de premier plan, comme le rappelait la récente controverse qui a opposé la police fédérale américaine à la firme Apple quant à l'importance du décryptage de données numériques dans la lutte contre le terrorisme?

\section{Christophe Didier}

